\title{
RUMAH ABU MUARA KARANG
}

\author{
Oscarius Lufti ${ }^{1)}$, Agustinus Sutanto ${ }^{2)}$ \\ 1)Program Studi S1 Arsitektur, Fakultas Teknik, Universitas Tarumanagara, oscariusl@yahoo.com \\ 2)Program Studi S1 Arsitektur, Fakultas Teknik, Universitas Tarumanagara, berpikirteoripraksis@gmail.com
}

Masuk: 13-07-2020, revisi: 01-08-2020, diterima untuk diterbitkan: 24-09-2020

\begin{abstract}
Abstrak
Berawal dari isu dimana terdapat sebuah batasan secara fisik yang memisahkan antara dunia kehidupan dan dunia kematian yang menimbulkan kesan yang tidak baik terhadap kematian. Manusia yang masih hidup dapat melakukan ritual untuk berinteraksi secara rohani dengan dunia kematian. Dari hal ini dapat dikatakan bahwa masih terdapat peluang untuk terjadinya interaksi antara dunia kehidupan dan dunia kematian. Pemanfaatan teknologi diterapkan dalam perancangan proyek untuk menciptakan arsitektur yang menjadi wadah dimana terjadi interaksi antara dunia kehidupan dan dunia kematian. Dunia kematian akan berbaur dengan pengunjung dan sebaliknya sehingga terjadi interaksi. Membawa tema "Third Place" dalam konsep perancangan proyek yang diusulkan, perancangan rumah abu tidak akan bersifat tertutup. Rumah abu dapat dijadikan sebagai ruang arsitektur yang dapat dinikmati oleh masyarakat tanpa terkecuali. Interaksi tidak hanya terjadi dengan sesama manusia yang masih hidup, tetapi juga dapat terjadi dengan mereka yang sudah meninggal dengan bantuan teknologi yang ada. Dengan ini pandangan terhadap rumah abu yang bersifat tertutup dapat dihilangkan.
\end{abstract}

\section{Kata kunci: Interaksi; Kehidupan; Kematian; Rumah Abu}

\begin{abstract}
Starting from the issue where there is a physical boundary that separates the world of life and the world of death which gives a bad impression of death. Living humans can perform rituals to interact spiritually with the world of the dead. From this it can be said that there are still opportunities for interaction between the living world and the world of death. Utilization of technology is applied in the design of projects to create architecture that becomes a container where interactions occur between the living world and the world of death. The world of death will mingle with visitors and vice versa so that interaction occurs. Carrying the theme "Third Place" in the proposed project design concept, the design of the columbarium will not be closed. Columbarium can be used as an architectural space that can be enjoyed by the community without exception. Interaction not only occurs with fellow human beings who are still alive, but also can occur with those who have died with the help of existing technology. With this view of the closed columbarium can be removed.
\end{abstract}

Keywords: Columbarium; Death; Interaction; Life

\section{PENDAHULUAN}

\section{Latar Belakang}

Dalam sebuah kehidupan terdapat dua dunia, yaitu kehidupan yang merupakan aktivitas sehari-hari dan kematian yang menjadi akhir dari kehidupan. Kematian merupakan bagian dari kehidupan yang pasti akan terjadi. Sebuah kematian dipandang sebagai sesuatu yang menyedihkan bagi sebagian besar masyarakat, karena terjadi perpisahan secara fisik yang tidak dapat dihindari. Tidak ada interaksi yang dapat dilakukan secara fisik antara kehidupan dan kematian. Dibalik ironi yang terjadi dibalik kematian, terdapat peluang untuk terjadinya interaksi antara dunia kehidupan dan kematian. Manusia yang masih hidup masih dapat mendoakan manusia yang sudah meninggal. Dari kegiatan ini, masih menunjukan ada sebuah interaksi yang dapat dilakukan walaupun secara fisik. Dalam menerjemahkan tema Third Place 
sebagai tempat dimana orang-orang dapat berkumpul, perancangan proyek ini bertujuan untuk menciptakan wadah dimana dunia kehidupan dan dunia kematian dapat bertemu dan berinteraksi. Akan terjadi kegiatan antara dua dunia, kehidupan dan kematian.

\section{Rumusan Permasalahan}

Bagaimana sebuah arsitektur menciptakan ruang yang menjadi wadah interaksi antara dunia kehidupan dan kematian?

\section{Tujuan}

Tujuan dari studi terhadap latar belakang dan permasalahan yang diangkat adalah menciptakan ruang yang dapat mewadahi interaksi antara dunia kehidupan dan dunia kematian.

\section{KAJIAN LITERATUR}

\section{Third Place Oleh Per Ahrbom}

"It's a place where you might meet your family for a while in the middle of the day. They might drop by to say hello when they've been shopping, and you can sit together in the winter garden." (Per Ahrbom, 2016)

Dalam wawancaranya dengan AMF, Per Ahrbom (2016) menjelaskan bahwa Third Place datang dari keinginan masyarakat yang membutuhkan tempat berbelanja dan perkantoran. Tetapi sebagai masyarakat, mereka juga membutuhkan rumah. Menurut Per Ahrbom, Third Place merupakan sebuah tempat yang berada di antara tempat-tempat yang dibutuhkan masyarakat.

\section{"The Great Good Place" Oleh Ray Oldenburg}

"A place of refuge other than the home or workplace where people can regularly visit and commune with friends, neighbors, coworkers, and even strangers." (Oldenburg, 1989)

Third place lebih memperhatikan aspek sosial, yang berarti sebuah Third Place harus nyaman dan berkesan welcoming, kemudian menjadi sebuah tempat yang selalu dikunjungi. Third Place menjadi tempat dimana dapat bertemu dengan teman lama maupun berkenalan dengan teman baru. Berdasarkan "The Great Good Place" Oleh Oldenburg (1989), ada beberapa kriteria dari Third Place.

\section{a. On Neutral Ground}

Tempat yang dimana semua orang dapat datang, berkumpul, dan pergi sesuka mereka. Kemudian tidak ada satu pihak yang dijadikan sebagai penguasa di tempat tersebut sehingga siapapun yang datang ke tempat itu akan merasa berada di rumah dan merasa nyaman.

b. The Third Place as Leveler

Menjadi sebuah tempat yang menyamaratakan, dimana semua orang yang datang memiliki kebebasan untuk menggunakan tempat tersebut. Masyarakat dapat mengakses suatu tempat tanpa harus memiliki suatu keanggotaan tertentu.

c. Conversation is the Main Activity

Percakapan dalam Third Place mungkin pada awalnya dimulai dari senyuman, twinkling eyes, bersalaman, ataupun menepuk bahu sebagai interaksi awal, yang kemudian akan dipertahankan dengan melakukan sebuah percakapan. Third Place harus menyediakan tempat yang terbuka atau tidak membatasi individu dimana setiap orang yang datang ke tempat tersebut akan melakukan interaksi awal hingga bercakap. Percakapan yang terjadi memungkinkan menarik individu lain untuk bergabung ke dalam percakapan tersebut.

d. Accessibility and Accommodation

Third Place merupakan tempat bagi semua orang tanpa ada batasan yang menhalangi orang untuk menuju ke tempat tersebut. Accessibility and Accommodation memiliki 
maksud agar sebuah Third Place mengfasilitasi seluruh masyarakat untuk dapat mencapai dan nyaman, termaksud bagi para difable. Difable harus dapat mengakses Third Place tanpa hambatan.

e. The Regulars

Sebuah Third Place tidak mengeksklusifkan kelompok tertentu. Third Place merupakan fasilitas umum sehingga setiap orang yang masuk ke dalamnya merasa nyaman.

f. A Low Profile

Sebuah Third Place dapat didatangi oleh semua orang dari berbagai macam latar belakang. Sebuah Third Place memiliki tampilan yang low profile agar tidak mengintimidasi masyarakat yang datang. Masyarakat yang datang harus merasa bahwa mereka juga layak dan nyaman berada di tempat tersebut.

g. The Mood is Playful

Third Place merupakan tempat yang menyenangkan bagi masyarakat yang berada disekitarnya. Playful tidak hanya sebatas tempat bermain saja, tidak menutup kemungkinan terjadi sebuah percakapan atau interaksi yang serius di dalamanya. Inti dari aspek ini adalah di sebuah Third Place, penerimaan dan sukacita lebih mendominasi dari pada rasa kecemasan dan keterasingan.

h. A Home Away From Home

Sebuah Third Place juga menjadi sebuah "home" bagi masyarakat di sekitar. Third Place yang menjadi sebuah "home" merupakan tempat dimana terbentuk unit sosial karena interaksi yang terjadi. Kemudian unit sosial tersebut menjadi sebuah "keluarga". Setiap orang yang datang harus merasakan perasaan tersebut sehingga Third Place menjadi lingkungan yang menyenangkan.

\section{Open Architecture oleh Herman Hertzberger}

"Open Architecture : A lot to do with emphaty" (Hertzberger, 2016). Menurut Herman Hertzbeger (2016), Arsitektur harus lebih mempermasalahkan bagaimana cara arsitektur merangkul dan dapat mewadahi kebutuhan masyarakat. Sebuah arsitektur dapat diterima masyarakat jika masyarakat merasa nyaman.

\section{Kuliah Umum Suryono Herlambang}

Suryono Herlambang (2020), dalam kuliah umumnya mengatakan bahwa Third Place merupakan sebuah Opennes yang memiliki kriteria fisik dan non fisik.

a. Transparent (Fisik)

Faktor Transparent memiliki hubungan dengan keterbukaan view. Third Place tidak hanya dapat dinikmati oleh orang yang berada di dalamnya saja, tetapi Third Place juga dapat dinikmati oleh orang yang berada di sekitarnya. Sebagai contoh ketika di sebuah Third Place diadakan sebuah acara, maka arsitektur Third Place harus memberi akses kepada orang yang berada di dalam maupun di sekitarnya.

b. Void

Sebuah Third Place memiliki penampilan yang ramah dengan konteks lingkungan sekitarnya. Idealnya arsitektur Third Place tidak menciptakan Third Place yang berpenampilan menonjol dalam lingkungan.

c. Acces

Flow yang terjadi di dalam Third Place akan mempengaruhi perancangan. Setiap orang yang masuk ke dalam Third Place berasal dari berbagai kalangan dan memiliki berbagai tujuan. Flow dalam Third Place mengfasilitasi kebutuhan orang yang datang atau hanya sekedar melewati tempat tersebut.

d. Porosity

Third Place selalu memiliki hubungan dan keterikatan dengan lingkungan disekitar seperti alam dan neighborhood. Konteks alam dan neighborhood membentuk Third place yang 
seakan menyatu dengan lingkungan sekitar agar masyarakat tetap merasakan koneksi antara Third Place dengan lingkungan maupun rumah.

e. Program

Program memiliki hubungan dengan aktivitas yang berada dalam sebuah Third Place. Aktivitas dalam Third Place merupakan cara untuk berinteraksi dengan sesama orang yang datang ke dalam Third Place tersebut. Program aktivitas tidak menutup kemungkinan bagi aktivitas bersama maupun aktivitas individu, tetapi program tersebut dapat mengintegerasikan antara kedua jenis aktivitas tersebut.

f. Placeness

Setiap orang akan merasakan keberadaan suatu tempat dengan karakter dari tempat tersebut. Third Place yang memiliki konteks dengan lingkungan sekitar juga memiliki karakter yang menjadi pembeda antara berada di dalam tempat tersebut dengan di luar tempat tersebut.

g. Playfulness

Sebuah Third Place merupakan tempat yang menyenangkan bagi seluruh masyarakat tanpa terkecuali. Tidak ada perasaan resah dan tidak nyaman ketika berada di sebuah Third Place.

\section{Reincarnation by Hans Wilhelm}

Hans Wilhelm (2012) menjelaskan dalam teori reinkarnasi bahwa "Hidup merupakan lingkaran dari sebuah siklus dimana terdapat hubungan antara manusia dan dunia." Dalam kehidupan ini terdapat sebuah interaksi yang terjadi antara manusia dan dunia. Interaksi ini memberikan manfaat kepada kedua belah pihak. Manusia memberikan manfaat terhadap keberlangsungan dunia kemudian dunia memberikan manfaat bagi kehidupan manusia.

\section{METODE}

Proses laporan ini diawali dengan permasalahan dimana terdapat batasan yang memisahkan kehidupan dan kematian secara fisik sehingga dunia kematian ditinggalkan atau dilupakan begitu saja. Untuk menjawab permasalahan ini, penulis mengacu kepada teori reinkarnasi yang dikemukakan oleh Hans Wilhelm (2012) yang mengatakan bahwa terdapat siklus yang berhubungan antara manusia dan dunia. Kemudian dilanjutkan dengan melakukan studi terhadap teknologi dan penerapannya sehingga dapat menciptakan ruang interaksi antara manusia yang masih hidup dan kematian. Setelah itu dilakukan studi terhadap tipologi terhadap ruangan yang diperlukan dan mencari studi literatur dari buku maupun internet yang pada akhirnya menjadi dasar acuan dalam perancangan proyek tugas akhir ini.

\section{DISKUSI DAN HASIL}

\section{Isu dan Permasalahan}

Columbarium merupakan tempat untuk menyimpan abu jenazah yang pada hari tertentu keluarga dari jenazah tersebut akan datang dan melakukan ritual untuk mendoakan arwah jenazah. Pada saat itu terjadi sebuah interaksi antara manusia yang masih hidup dengan kematian, tetapi jika tidak terdapat acara atau ritual, rumah abu bukanlah tempat yang pada umumnya dikunjungi. Hal ini menjadikan rumah abu sebagai tempat yang tertutup dan terpisah dari dunia kehidupan. Jika arsitektur terhadap rumah abu hanya sebatas tempat penyimpanan abu jenazah, maka columbarium merupakan sebuah ruang arsitektur yang dingin. 


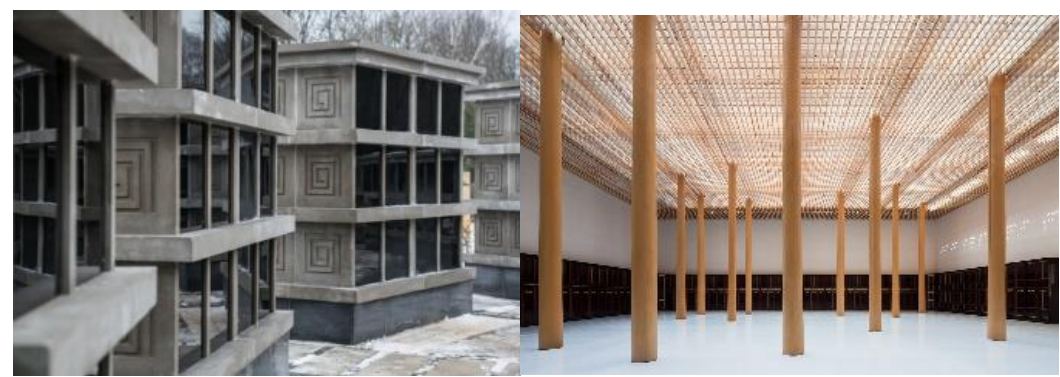

Gambar 1. Ruang Penyimpanan Abu

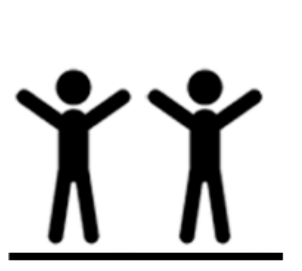

L I FE Sumber: Google Image

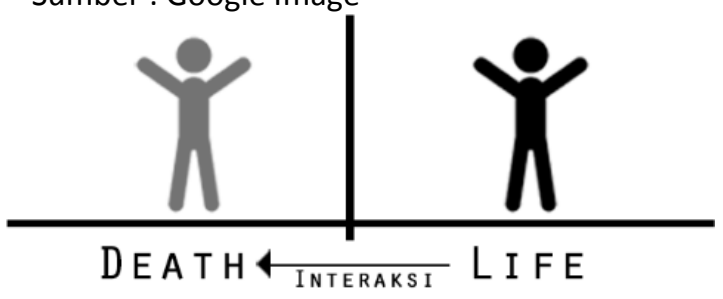

MEMORY

PRAYER

ACT I V I T Y

Gambar 2. Hubungan Hidup \& Mati

Sumber : Penulis, 2020

\section{Analisis Lokasi}

Lokasi yang dipilih untuk perancangan proyek tugas akhir ini terletak di Muara Karang, Jakarta Utara. Kawasan Muara Karang merupakan kawasan hunian dengan mayoritas penduduk keturunan China. Lokasi ini dipilih karena pada dasarnya Muara Karang terletak di antara kawasan Pantai Indah Kapuk sebagai kawasan perumahan dan Pluit sebagai akses masuk dari pusat kota menuju kawasan hunian di Muara Karang dan Pantai Indah Kapuk. Jalan Muara Karang Raya merupakan akses utama yang dilalui sebagai jalur penghubung dan juga menjadi jalur utama dalam Kawasan Muara Karang. Terdapat penjual makanan, café, dan pasar di Jalan Muara Karang Raya. Hal ini menjadikan Muara Karang sebagai kawasan "Third Place" bagi masyarakat Muara Karang dan juga masyarakat yang melintasi kawasan Muara Karang.

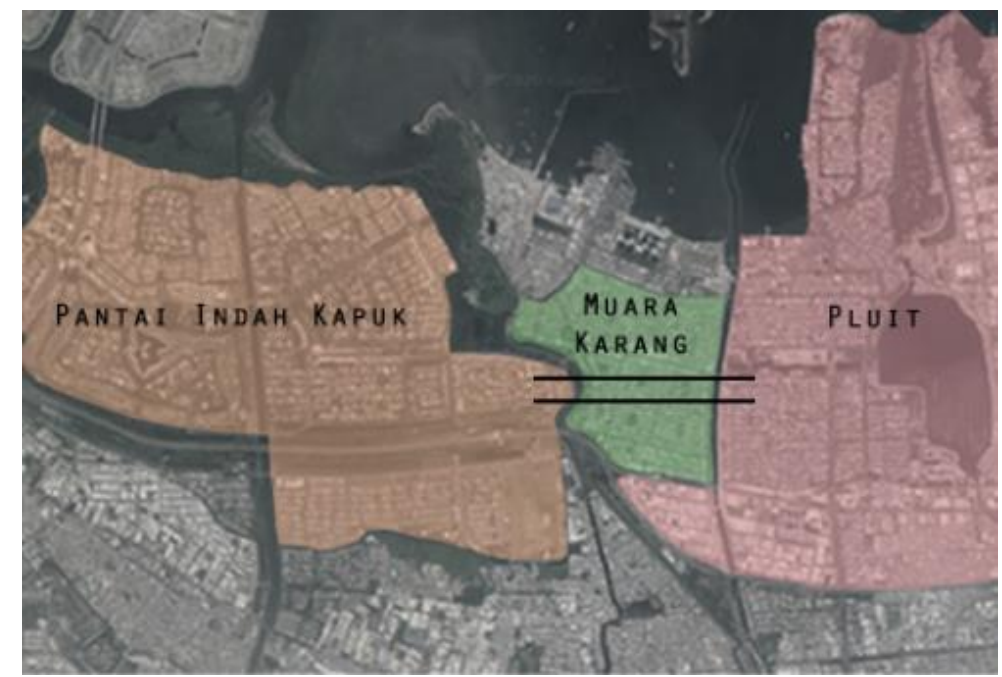

Gambar 3. Foto Udara Sekitar

Sumber : Penulis, 2020 


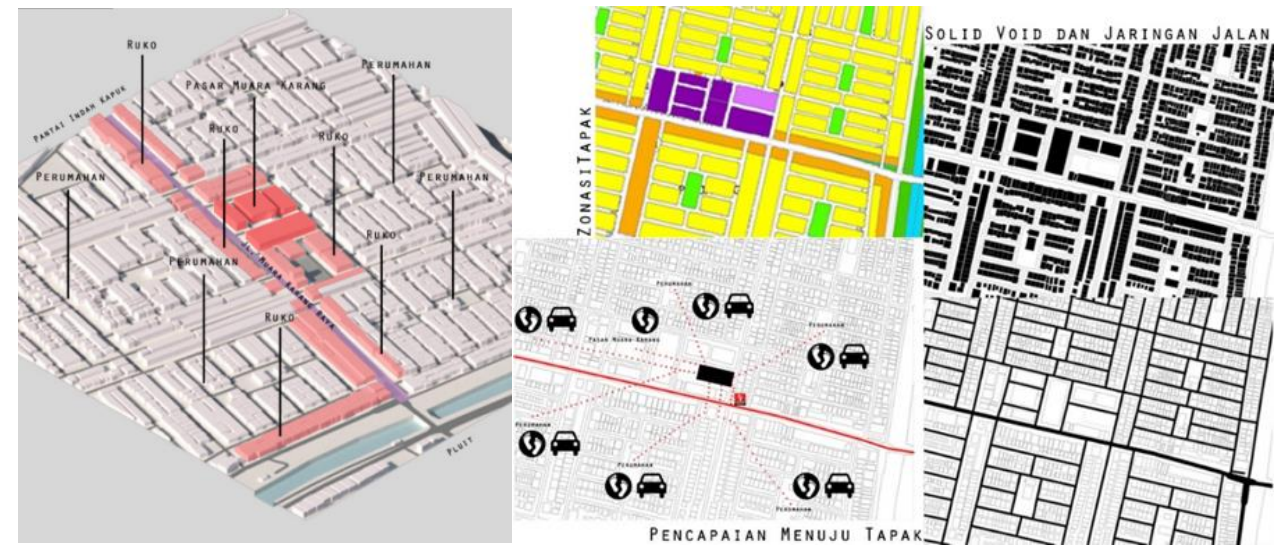

Gambar 4. Kawasan Muara Karang

Sumber: Penulis, 2020

Pola dari kawasan Muara Karang ini terbentuk dari area perumahan yang mengelilingi kawasan Muara Karang, area komersil di sepanjang Jalan Muara Karang Raya, dan area Pasar Muara Karang yang terletak di tengah kawasan Muara Karang serta menjadi area pusat kegiatan ekonomi untuk kawasan Muara karang. Area Pasar Muara Karang merupakan titik pusat berkumpulnya masyarakat di kawasan Muara Karang. Area Pasar Muara Karang meliputi bangunan utama pasar sebagai pusat kegiatan, pasar yang berada di pinggiran jalan, dan tempat makan yang terdapat di sekitar area pasar. Area Pasar Muara Karang terhubung langsung dengan transportasi pengumpan Transjakarta sehingga memudahkan masyarakat yang berasal dari luar kawasan Muara untuk mencapai tapak. Lokasi Area Pasar Muara Karang terletak tepat di tengah kawasan Muara Karang dan dapat ditempuh dengan berjalan kaki oleh masyarakat Muara Karang karena masih berada di dalam radius jarak berjalan kaki.

\section{Profil Tapak}

Berada di Jl. Niaga, Muara Karang, Jakarta Utara. Tapak terletak di Area Pasar Muara Karang, tepatnya di Jalan Niaga. Tingginya mobilitas dan pergerakan di sekitar site menjadikan site di Jalan Niaga ini sangat tepat untuk proyek Third Place. Hal ini memungkinkan banyaknya orang yang datang menuju tapak. Fungsi di sekitat tapak didominasi oleh pedagang makanan dan tempat berkumpul bagi masyarakat yang berada di area Pasar Muara Karang

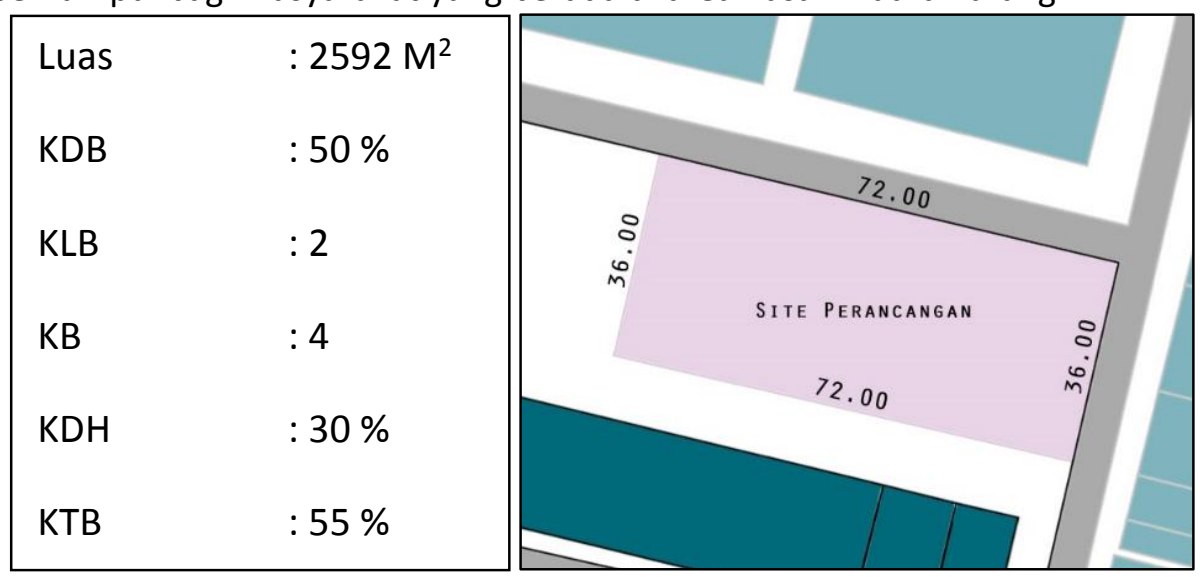

Gambar 5. Profil Tapak

Sumber: Penulis, 2020 


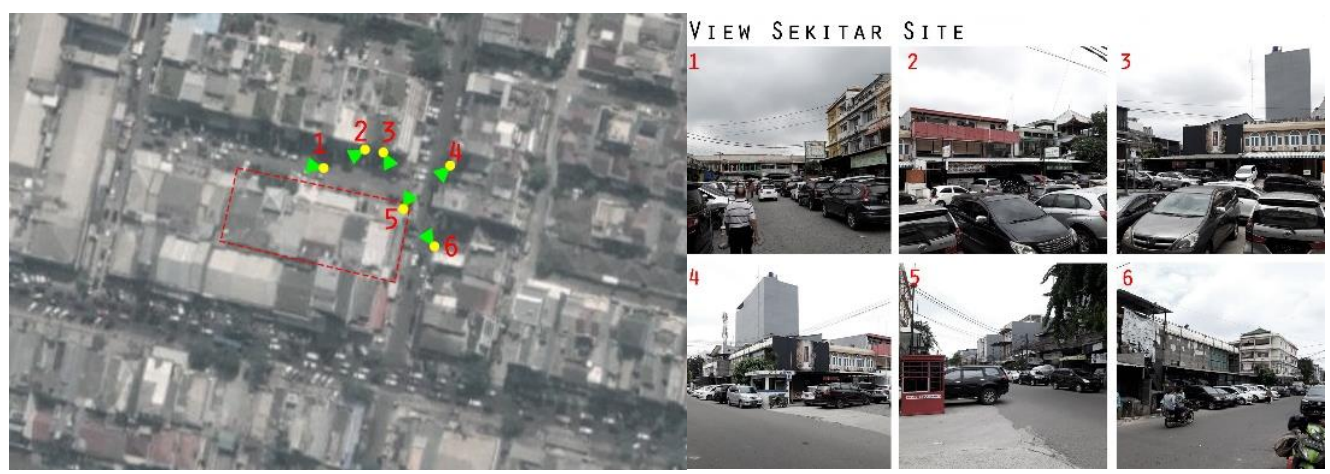

Gambar 6. Foto Sekitar Site

Sumber : Penulis, 2020

Lokasi tapak juga mendukung perancangan sebuah Third Place karena lokasi tapak memiliki permeabilitas yang baik. Terdapat halte bus pengumpan Transjakarta di sekitar site. Penumpang yang turun di halte tersebut akan melewati lokasi site untuk menuju Pasar Muara Karang.

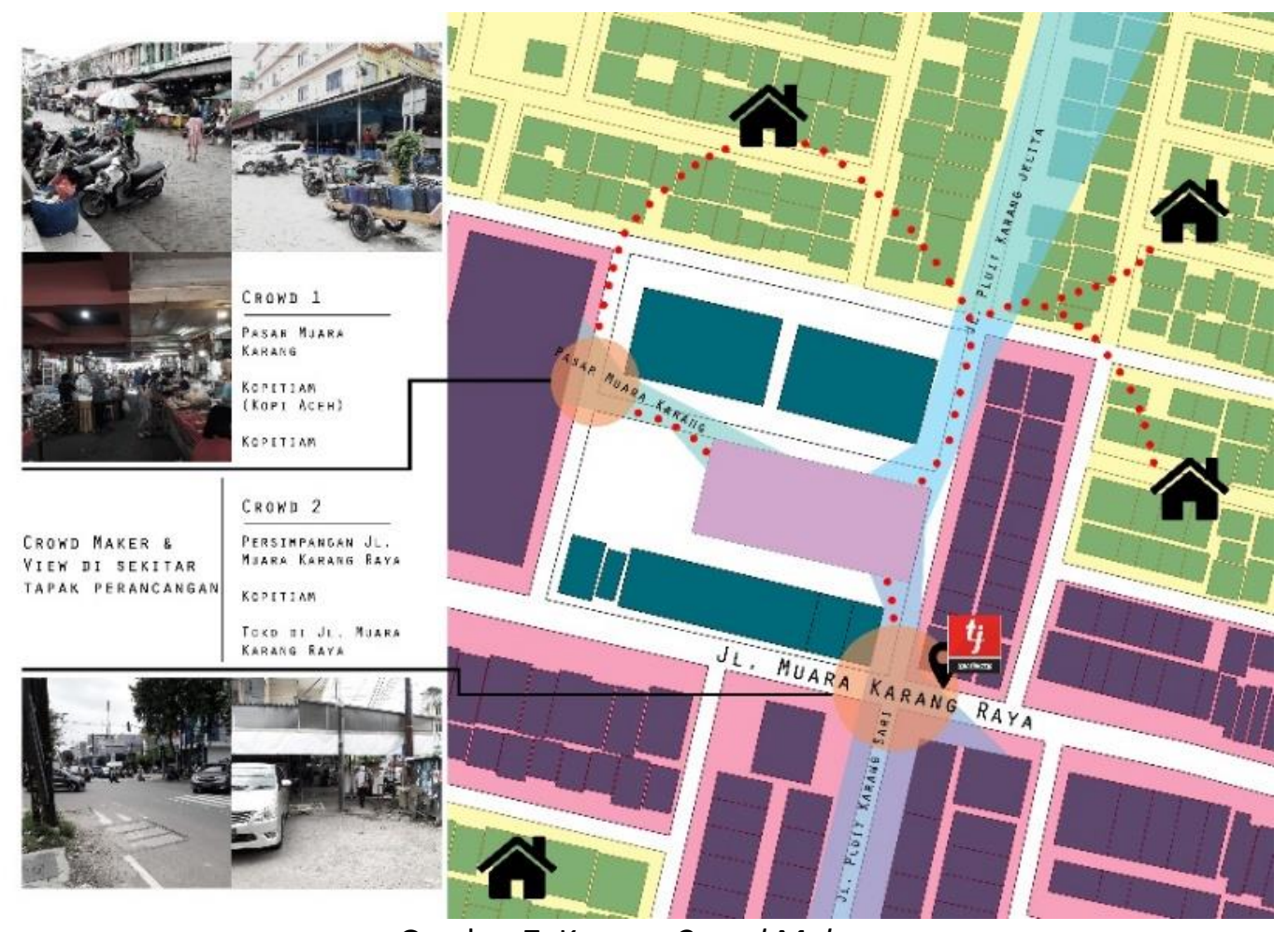

Gambar 7. Konsep Crowd Maker

Sumber: Penulis, 2020

Proyek yang diusulkan adalah perancangan rumah abu. Rumah abu yang diusulkan memiliki perbedaan dengan rumah abu pada umumnya. Rumah abu yang diusulkan akan lebih terlihat sebagai taman agar arsitektur ruang yang diciptakan akan lebih hidup. Abu jenazah tidak akan disimpan di dalam petak-petak penyimpanan abu, tetapi abu jenazah akan dilebur dengan media tanam dan bibit sehingga dapat bertumbuh menjadi tanaman yang akan menjadi bagian dari taman. Abu jenazah mengandung mineral yang dapat mendukung pertumbuhan tanaman. Tanaman yang ada tidak hanya menjadi tanaman untuk merimbunkan taman, tetapi dapat menjadi suplai kebutuhan makanan manusia. Dalam hal ini terjadi interaksi hubungan timbal balik antara dunia kehidupan dan dunia kematian. Dalam proyek ini juga terdapat ruang ruang yang mendukung kegiatan spiritual seperti ruang dan ruang ritual. 


\section{Program}

Tabel 1. Konsep Gagasan dan Program

\section{Program}

\section{Public Garden}

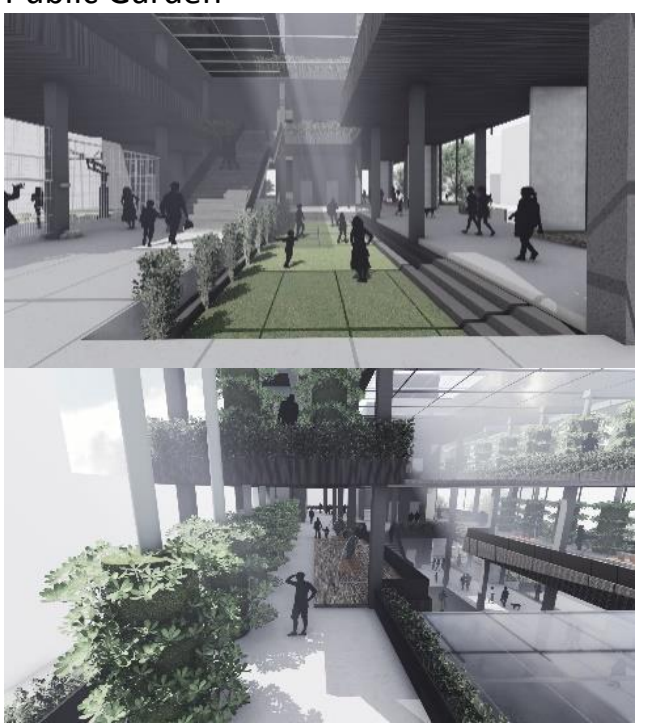

\section{Konsep}

Public Garden merupakan area yang paling umum dalam proyek ini. Di tempat ini seluruh pengunjung dapat berkumpul untuk melakukan kegiatan olahraga dan berbincang. Kegiatan olahraga dan berbincang diambil dari kontekstual sekitar site. Untuk kegiatan olagraga diambil dari alur kegiatan masyarakat yang pergi berolahraga dan kemudia pergi ke Pasar Muara Karang untuk berbelanja atau makan. Karena hal ini, area olahraga idmasukan ke dalam program agar terdapat tempat olahraga yang lebih dekat dengan Pasar Muara Karang. Kemudian untuk area berbincang diambil dari kegiatan masyarakat sekitar yang senang berkumpul dan berbincang di kedai kopi atau tempat berkumpul lainnya di sekitar Pasar Muara Karang.

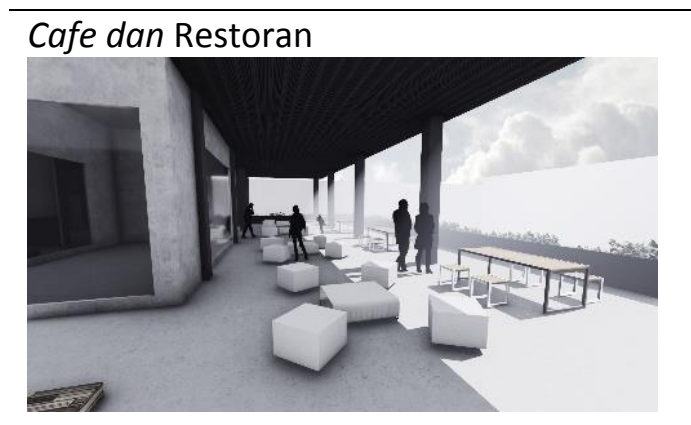

Program ini pada dasarnya merupakan sarana yang dapat menarik crowd dari sekitar site. Lokasi sekitar site didominasi oleh penjual makanan dan tempat untuk berkumpul. Kemudian program ini merupakan kelanjutan dari program Public Garden. Program ini juga menjadi tempat berkumpul untuk masyarakat yang berziarah ke rumah abu.

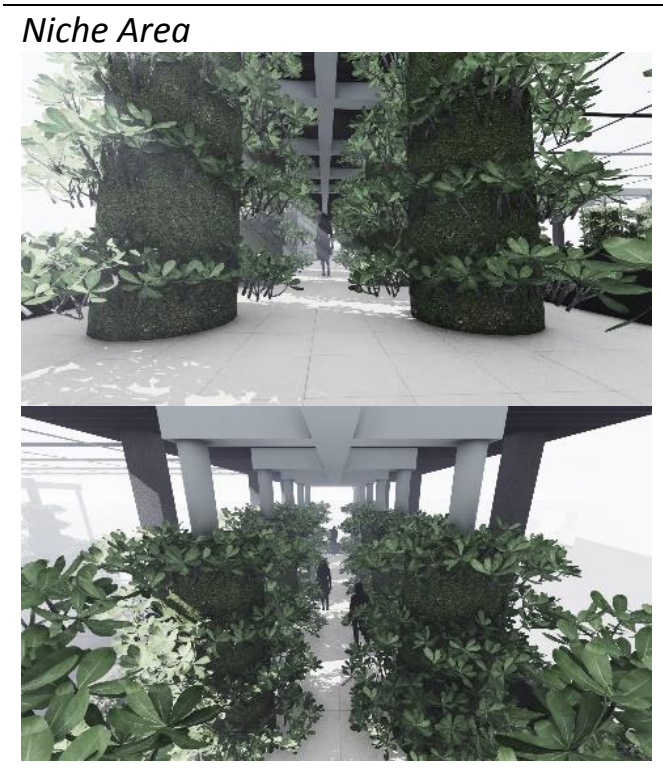

Niche Area merupakan program inti dari rumah abu yang diusulkan. Niche Area tidak berupa blok atau petak penyimpanan abu, tetapi merupakan petak-petak yang besrisi peleburan antara abu jenazah dengan bibit tanaman dan media tanam.

Pray and Ritual Area

Program ini merupakan fasilitas pendukung dari fungsi rumah abu. Program ini meliputi ruang doa dan ruang ritual yang pada hari tertentu digunakan untuk acara spiritual. 


\section{Gubahan Massa dan Skema Desain}
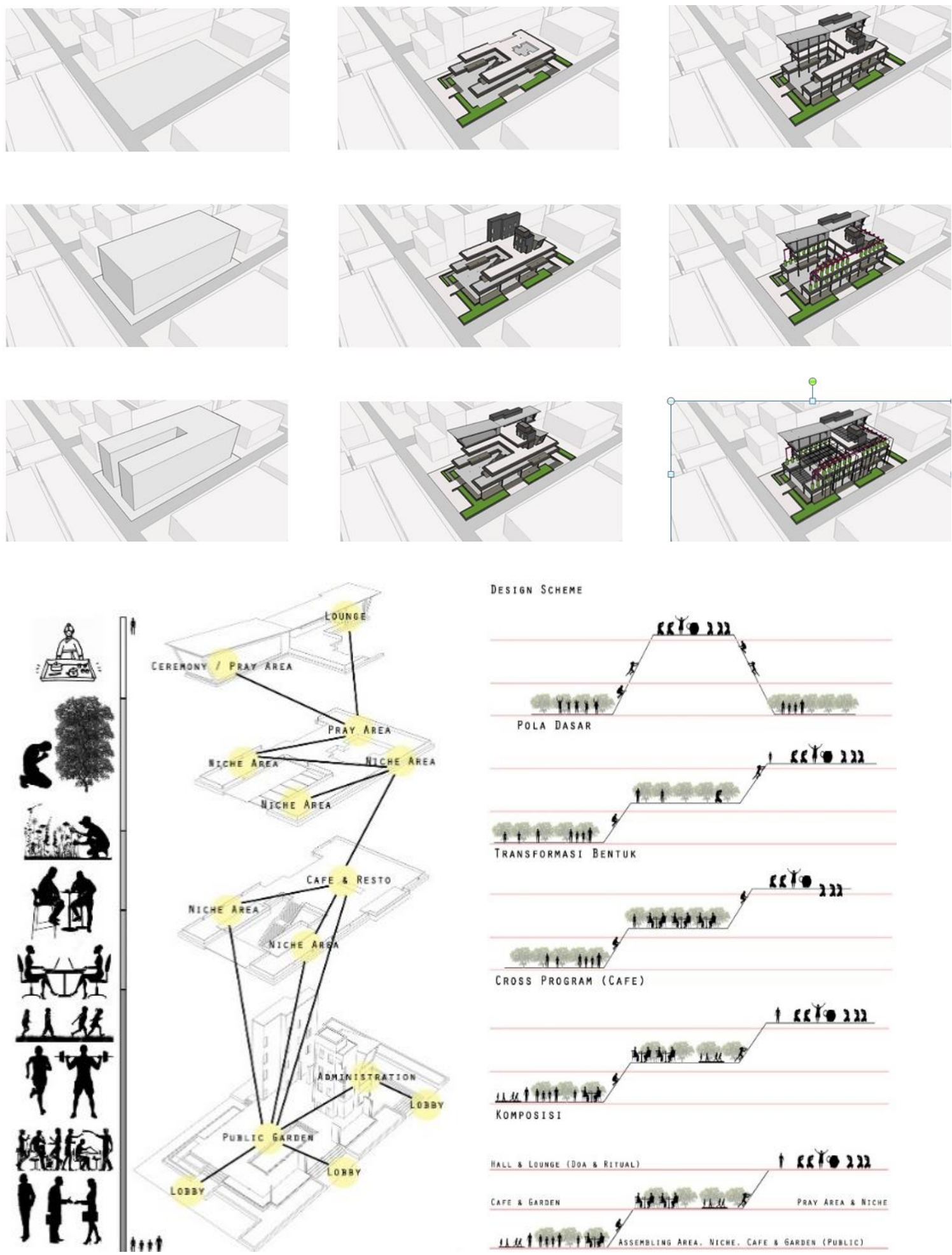

Gambar 8. Konsep Pembentukan Gubahan Massa dan Skema Desain

Sumber: Penulis, 2020

Secara umum, desain yang dihasilkan tidak memiliki pemis

ah secara fisik antara rumah abu dengan lingkungan sekitarnya. Terjadi hubungan interaksi antara pengunjung dengan rumah abu dan juga lingkungan sekitar dengan rumah abu. Teknologi yang digunakan dalam perancangan rumah abu ini terletak pada penyimpanan abu. 
Setiap pilar penyimpanan abu memiliki saluran air sebagai sarana suplai air untuk tanaman hasi peleburan abu dengan media tanam dan bibit.

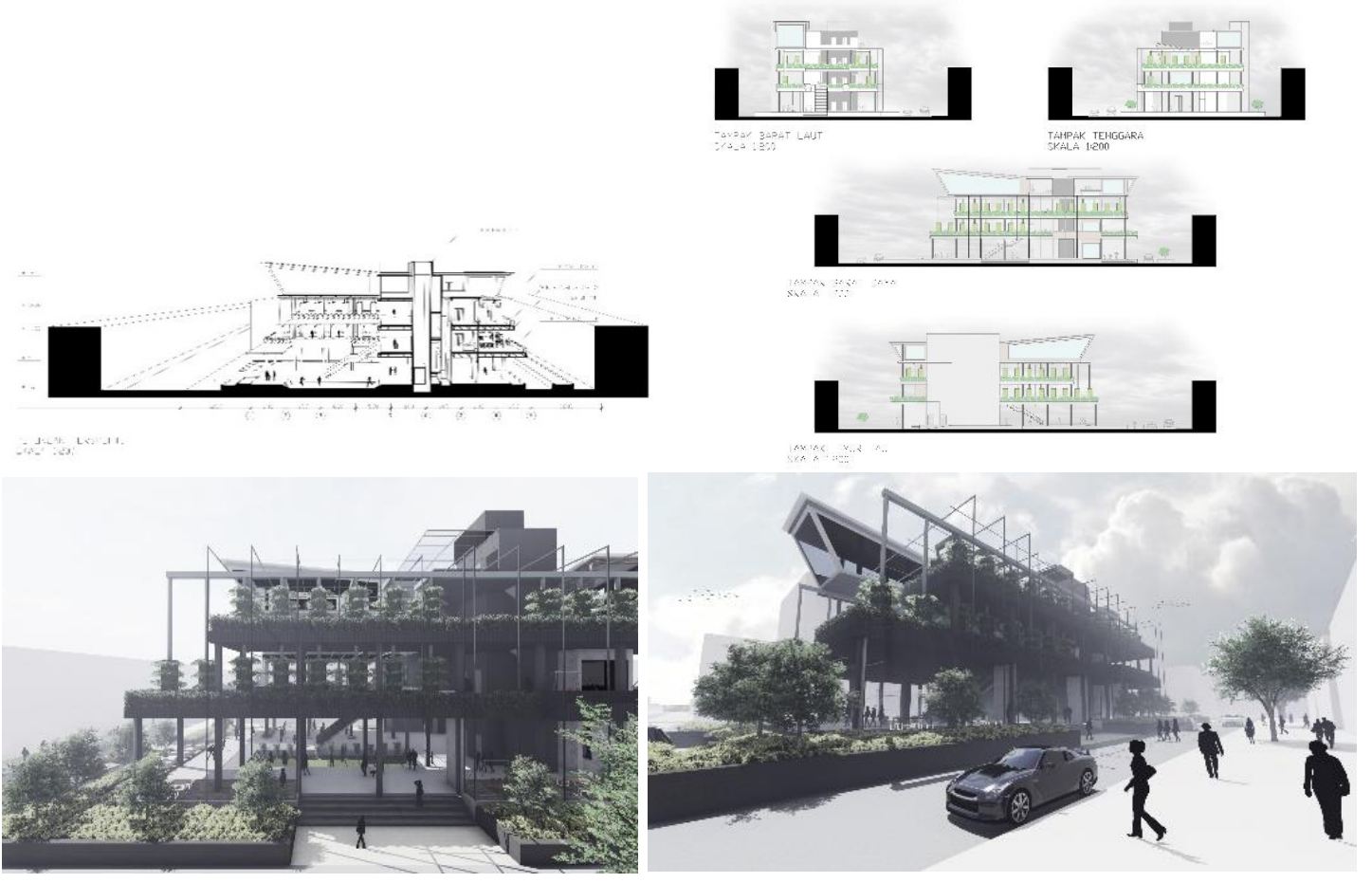

Gambar 9. Gambar Perancangan dan Visualisasi Proyek Sumber : Penulis, 2020
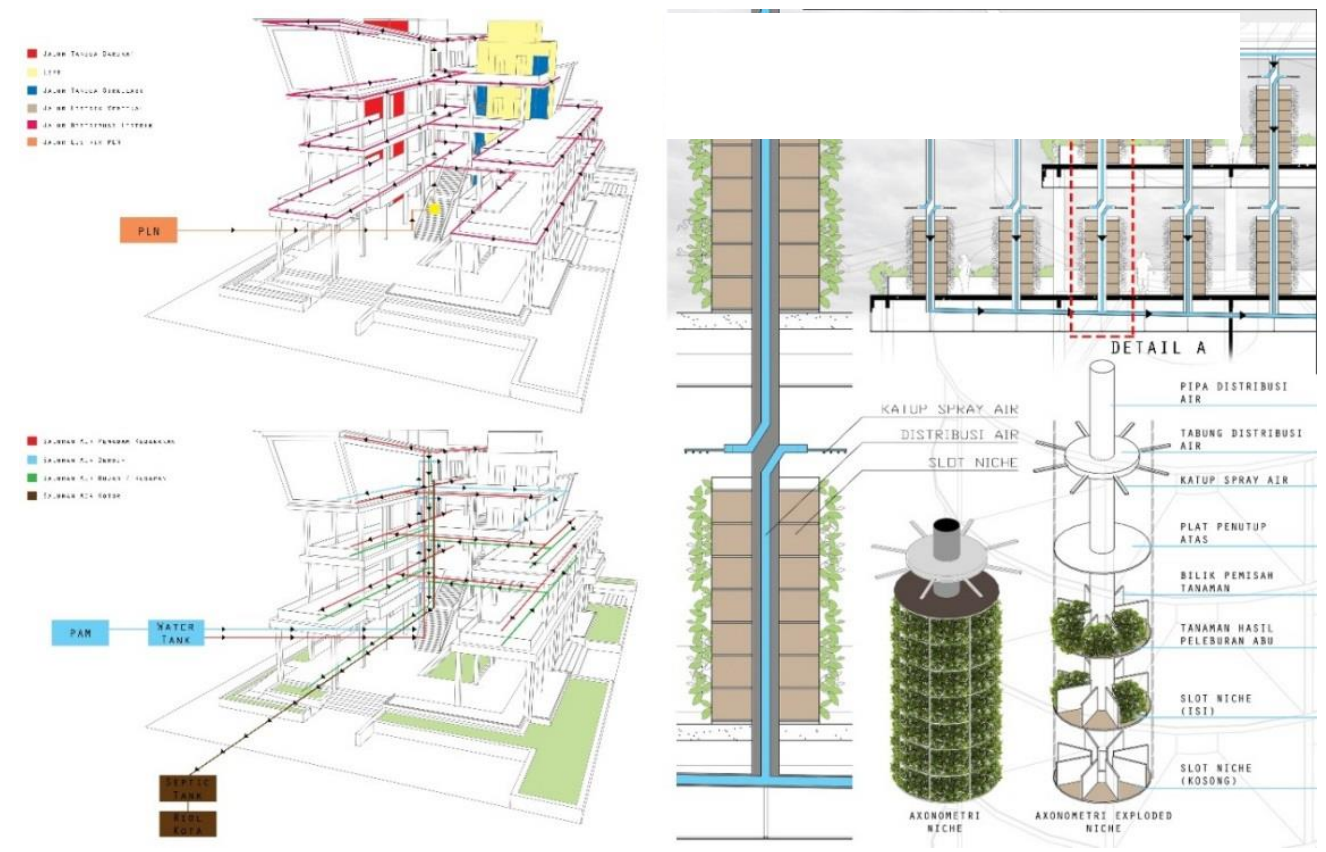

Gambar 10. Skema Perancangan Utilitas dan Penyimpanan Abu Sumber: Penulis, 2020

Pada sistem utilitas, air akan didistribusikan dengan pipa yang air menuju pilar penyimpanan abu. Kemudian air akan disiramkan ke tanaman dengan cara spray. Pipa air bersih mendistribusikan air dari atas dan kemudian turun memasuki masing-masing pilar penyimpanan abu. 


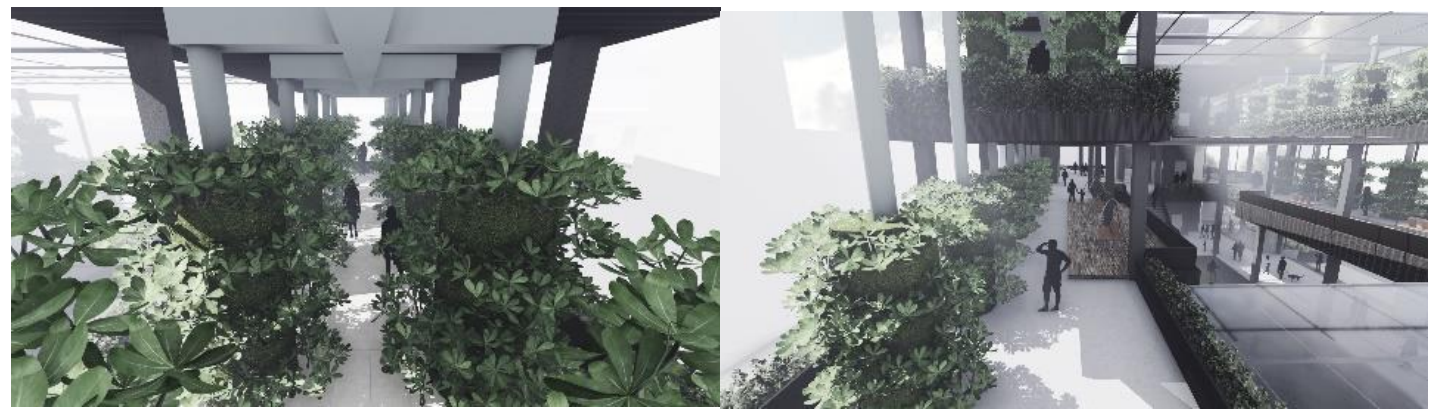

Gambar 11. Gambar Visualisasi Rancangan

Sumber: Penulis, 2020

\section{KESIMPULAN DAN SARAN}

\section{Kesimpulan}

Hubungan atau interaksi antara kehidupan dan kematian tidak hanya dapat dilakukan secara spiritual atau non-fisik, tetapi dengan bantuan teknologi, interaksi tersebut dapat terjadi secara fisik dan dapat saling menuntungkan. Hal ini memberikan gambaran bahwa kematian tidak selalu menjadi hal yang buruk tetapi dapat menjadi sesuatu yang bermakna dan bermanfaat bagi kehidupan.

\section{Saran}

Proyek ini merupakan model baru dalam hal penyimpanan abu. Tingginya kepadatan bangunan di dalam kota akan mengurangi lahan untuk pemakaman. Untuk pengembangannya, rumah abu dapat dijadikan sebagai satu kesatuan dalam bangunan yang padat kegiatan. Interaksi antara dunia kehidupan dan kematian dapat terjadi dimana saja dan dapat memberikan manfaat bagi kehidupan di sekitarnya.

\section{REFERENSI}

Herlambang, S. (2020, Februari). Open Architecture. Bahan Kuliah Umum di Universitas

Tarumanagara, Jakarta, Indonesia.

Oldenburg, R. (1999). The Great Good Place. New York: Da Capo Press.

Wilhelm, Hans. (2012). REINCARNATION explained by Hans Wilhelm.

Per A. (2016). The third place - Architect Per Ahrbom shares his thoughts on the Urban Escape Project.

Sutanto, A. (2020, Februari). Open Architecture: Third Place. Bahan Kuliah Umum di Univesitas

Tarumanagara, Jakarta, Indonesia. 
